\title{
A social-ecological systems approach to non-native species: Habituation and its effect on management of coqui frogs in Hawaii
}

\author{
Emily A. Kalnicky a,*, Mark W. Brunson ${ }^{a}$, Karen H. Beard ${ }^{\text {b }}$ \\ ${ }^{a}$ Department of Environment and Society and the Ecology Center, Utah State University, Logan, UT 84322-5215, USA \\ ${ }^{\mathrm{b}}$ Department of Wildland Resources and the Ecology Center, Utah State University, Logan, UT 84322-5230, USA
}

\section{A R T I C L E I N F O}

\section{Article history:}

Received 4 June 2014

Received in revised form 7 September 2014

Accepted 27 September 2014

Available online 28 October 2014

\section{Keywords:}

Eleutherodactylus coqui

Hawaii

Invasive

Private property

Social-ecological system

\begin{abstract}
A B S T R A C T
Non-native species introductions have the ability to affect both ecological and social systems, thus to address those outcomes both ecological and social influences on an invasion need to be understood. We use a social-ecological systems approach to investigate connections between human and ecological factors that affect efforts to control the non-native coqui frog (Eleutherodactylus coqui) on the island of Hawaii. The coqui frog is recognized as a 'pest' and 'injurious wildlife' by the Hawaii Department of Agriculture. Because the coqui occurs on many small private properties across the island, it is necessary to enlist private citizens in control efforts. Control efforts can include direct chemical control of the coqui as well as landscape manipulations that reduce habitat quality for the frog. On 85 private properties in 12 communities across the island, we measured the relationship between coqui abundance, residents' attitudes toward the coqui, their reported participation in control activities, and environmental variables that affect habitat quality for the frog. Residents' attitudes correlated with coqui frog abundance, but in an unexpected direction: People with more frogs on their property and those who owned that property tended to have less negative attitudes toward the coqui. In addition, negative attitudes toward the coqui were not significantly related to participation in control activities. Coqui abundance was related to a habitat variable, canopy cover, which can be manipulated by residents to reduce habitat quality and discourage coqui occupancy. Tolerance for this non-native species is likely to hinder attempts to engage residents in control efforts as the species' range on the island continues to expand. If this pattern of habituation is manifested with other non-native species considered to have potentially negative effects on the ecological or social environment, it would be important to recognize as early as possible because managers may be most effective at engaging citizens in control efforts before habituation becomes widespread.
\end{abstract}

(c) 2014 Elsevier Ltd. All rights reserved.

\section{Introduction}

At a most basic level, non-native species invasions have the potential to affect social as well as ecological systems. More specifically, non-native species can affect human health and economics as well as biodiversity of an invaded area (Mooney, 2005; Simberloff et al., 2013). Most non-native species are introduced via intentional or inadvertent transport by humans (Ruiz and Carlton, 2003). Defending against a non-native species introduction requires human action as well. Yet much remains unknown about the relationship between people's attitudes toward nonnative species, their activities intended to control these species, and the subsequent local presence or abundance. How directly are negative or positive beliefs about a species linked to an

\footnotetext{
* Corresponding author.

E-mail address: emily.kalnicky@gmail.com (E.A. Kalnicky).
}

individual's willingness to take action against that species? Must an invader be locally abundant before attitudes are sufficiently negative to lead to management action? Can one predict which types of individuals are most likely to take action against a species? Are there social attributes that might predispose an individual's property to be invaded? One reason researchers have been slow to answer such questions may be that doing so requires crossing disciplinary boundaries, using approaches drawn from both social and natural sciences. Recent attention to the dynamics of socialecological systems (Folke, 2006; Bodin and Tengö, 2012) has opened the door to cross-disciplinary approaches that can help us understand human aspects of non-native species invasions more fully.

We used a social-ecological systems (SES) framework to guide our study of factors that govern persistence of the introduced frog Eleutherodactylus coqui (colloquially, "the coqui") on the island of Hawaii. Since its accidental introduction from Puerto Rico to the 
island of Hawaii in the late 1980s, the coqui's range has increased (Kraus et al., 1999; Kraus and Campbell, 2002) and it is listed as one of the 100 "world's worst" invaders (ISSG, 2005) and is designated as a 'pest' and 'injurious wildlife' by the Hawaii Department of Agriculture (Beard and Pitt, 2012). The coqui is expected to continue expanding its range on the island, and eradication is no longer believed to be possible, even though control efforts have been quite successful on Oahu and Kauai while the populations were still restricted in range (Beard et al., 2009; Bisrat et al., 2012). One reason that eradication on the island of Hawaii is viewed as no longer possible is because the coqui is often found on private properties, which means that landowners have to agree to and even participate in control operations. If some landowners fail to participate in control, a mosaic of refugia is created from which reinvasion can occur. For example, eradication on Kauai was hindered for many years because of a single landowner (Beard, pers. obs.). Building on the work of scientists who have taken an SES approach to understand interactions between people and their home environment in urban settings (Chowdhury et al., 2011; Cook et al., 2012), we focused on environmental and social factors that affect the capacity to control the coqui at the private property level.

\subsection{Social complexities surrounding non-native species}

Perceptions of non-native species can be culturally or historically based, resulting in strong attitudes toward the species (Coates, 2006) that are related to the management practices people believe are appropriate (Fraser, 2006). Attitudes toward different forms of management for non-native vertebrate species have been related to the specificity of the management method and the humaneness (Barr et al., 2002; Fraser, 2006) and to socio-demographic factors, such as age and gender (Miller and Jones, 2005, 2006; Fitzgerald et al., 2007). These relationships are complex (Fitzgerald et al., 2007) and a greater understanding can be necessary for successfully managing an area (Reaser, 2001; Coates, 2006).

The more directly a non-native species affects a person, the more likely the individual is to understand the potential benefits of a management program designed to eradicate the species (Fraser, 2006). Thus management for non-native species can be dependent on coordination of managers and the effort of the general public to minimize costs and maximize effectiveness (Stokes et al., 2006; Epanchin-Niell et al., 2010).

\subsection{Specific ecological and social variables related to coqui frog invasion}

Control efforts for the coqui on the island of Hawaii consist of a mix of chemical, mechanical, and cultural methods. All are activities landowners can do themselves. Volunteer community groups conduct many of the control efforts on the island; for example, in $2008,43 \%$ of the area treated on the island was conducted by community associations (Anonymous, 2010). Currently the only approved and recommended chemical control consists of direct application of citric acid to frogs and/or frog eggs. Mechanical control, including hand-capture, traps, barriers, and hot water treatments, has mostly been employed in smaller, high-risk settings, such as nurseries. Cultural control includes checking plants at the nursery for coqui eggs or frogs before purchasing, and removing vegetation on a property because of frogs. Property owners are encouraged to spray suspected frog habitats directly with citric acid, eliminate frog habitat, inspect potted plants, and treat coqui-infested green waste (Pitt et al., 2012). If coqui control efforts were abandoned, island-wide effects on property values could increase, resort revenues could be negatively affected, and the risk of coqui spread to the other islands would increase (Anonymous, 2010). Therefore, it is important to understand whether people already living with the frog are willing to engage in coqui management behaviors.

Attitudes toward the coqui on the island of Hawaii are polarized, with many people thinking the species is a nuisance while others have launched campaigns to protect it (see Fujimori, 2001; Kraus and Campbell, 2002; Singer and Grismaijer, 2005). A major factor underlying the polarization in attitude is the sound the frog produces. The frog's name originates from the male's territorial and reproductive call (Stewart and Rand, 1992; Joglar, 1998; Rivero, 1998), which can reach up to $90 \mathrm{~dB}$ at $0.5 \mathrm{~m}$ (Beard and Pitt, 2005) and is mostly heard between dusk and dawn (Woolbright, 1985). As a result, property values in close proximity to frog infestation have in some cases been reduced (Kaiser and Burnett, 2006). It is possible that individuals who have negative attitudes toward the frogs and live in areas with high densities of frogs may change their attitude toward the frog to one of acceptance. This pattern has been shown in pest management behaviors for rice farmers (Heong et al., 1998) and is probably grounded in some level of self-interest (Hills, 1993), or a need to decrease the psychological discomfort that comes from holding internally inconsistent beliefs, ideas, or opinions (Festinger, 1957).

While densities of the frogs vary across sites, in the most optimal sites, densities reach as high as 91,000 frogs/ha (Beard et al., 2008). This is one of the highest densities ever recorded in the world for terrestrial frogs and well above what has been measured in its native Puerto Rico (Stewart and Woolbright, 1996). In addition, coquis have been shown to change invertebrate communities across the island (Choi and Beard, 2012), and increase growth rates of non-native plants (Sin et al., 2008). In Puerto Rico, coquis are found in most places as long as there is sufficient canopy cover and high humidity (Schwartz and Henderson, 1991). In Hawaii, coqui density is higher where there is higher understory density and prey availability (Beard et al., 2008; Kalnicky et al., 2013). Therefore, landscape alterations can affect habitat and potentially reduce coqui density.

However, little is known about how people's willingness to make such alterations is linked to their attitudes toward the coqui or to the current presence of frogs on their property (Beard and Pitt, 2005; Gonzalez-Pagan, 2007). Such information could be used to increase effectiveness for control strategies. In this research, we examined how frog abundance on private property was related to social and ecological factors (Fig. 1). We identified relationships between: (1) the abundance of coqui on a property and general attitude toward the coqui (link 1 on figure); (2) socio-demographic characteristics and attitude toward the coqui (link 2); (3) attitudes and reported participation in control activities (link 3); (4) abundance of frogs on a property and reported participation in control (link 4); and (5) relevant environmental variables and the abundance of frogs on a property (link 5).

\section{Methods}

We gathered data in May-August 2008 using a mixture of social and ecological methods. Semi-structured interviews of residents were conducted to determine attitudes and behaviors toward the coqui. Measures of ecological characteristics included coqui frog abundance on the interviewee's property as well as measures of habitat quality and prey density.

We selected 12 communities across the island of Hawaii using available GIS data from a Hawaii Invasive Species Council database to have full coverage of the island including areas with known presence and absence of frogs (Fig. 2). We then identified participants from each community by randomly selecting roads and then houses. If the randomly selected individual declined to participate, 


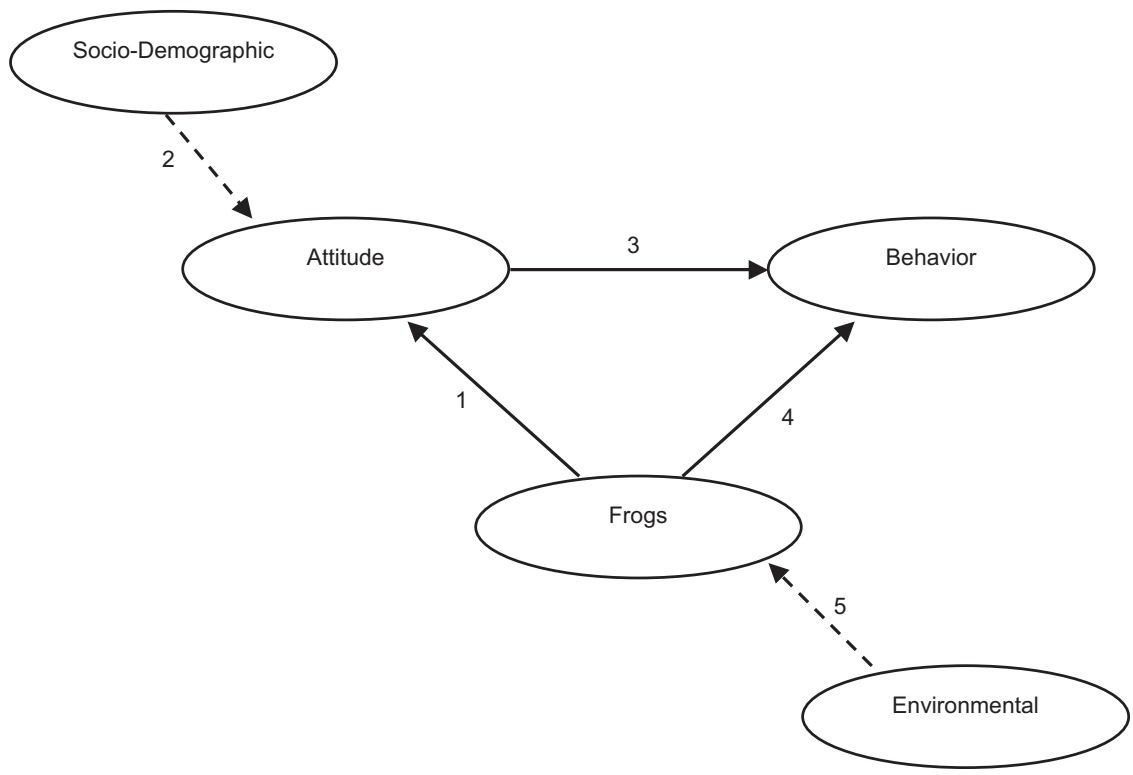

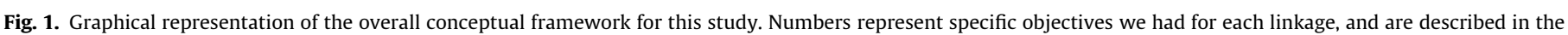
text.

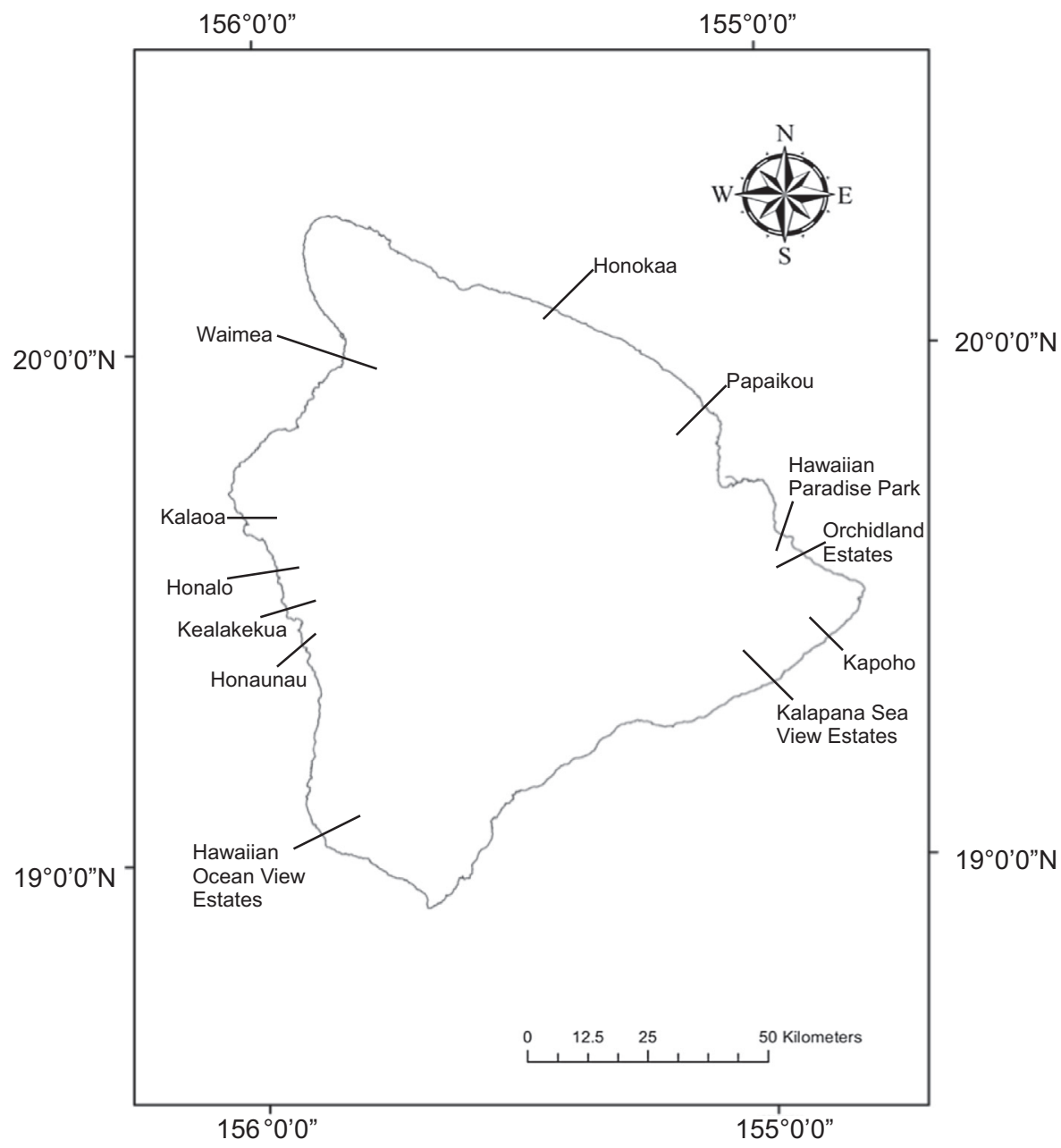

Fig. 2. Study locations on the island of Hawaii, May to August 2008.

we went to the next randomly selected house and repeated the process until there were seven properties within each community. To recruit participants in each of the 12 communities, every five days we traveled to the next community and spent one day recruiting participants. Using this approach we completed interviews and property surveys at 85 residences across the island, and a total of 
87 participants (one property had 3 unique participants, and we surveyed 8 properties in the first community).

We used a semi-structured interview technique to enable us to probe participants for deeper understanding (Kempton et al., 1995). Interviews were conducted at the participant's home and averaged $18 \mathrm{~min}$ in length. We also asked participants to provide demographic information. The specific questions we asked related to coqui attitude and coqui management behavior were:

1. In your opinion, what are some positive and negative aspects of the coqui frog?

2. Do you, or members of your household, do anything on your property for the coqui frog? (If yes... please describe).

While one researcher was conducting the interview, another researcher measured the size of the property and delineated randomly selected $10 \mathrm{~m} \times 10 \mathrm{~m}$ plots to measure property characteristics (i.e., invertebrate abundance and habitat structure/type). We determined the number of plots based on the property size: 1 or 2 plots if the property was less than $900 \mathrm{~m}^{2}, 3$ plots if the property was between 901 and $3600 \mathrm{~m}^{2}, 4$ plots if the property was between 3601 and $6400 \mathrm{~m}^{2}, 5$ plots if the property was between 6401 and $10,000 \mathrm{~m}^{2}$, and 6 plots for any property $>10,000 \mathrm{~m}^{2}$. We then randomly selected plots from all available plots on the property to survey.

In each of the randomly selected $10 \mathrm{~m} \times 10 \mathrm{~m}$ plots, we sampled invertebrates. We collected leaf litter from one $1 \mathrm{~m} \times 1 \mathrm{~m}$ subplot within each plot, and within $6 \mathrm{~h}$ extracted invertebrates using Berlese funnels. We collected flying insects on one $10 \mathrm{~cm}$ $\times 18 \mathrm{~cm}$ sticky trap per plot placed $0.75 \mathrm{~m}$ off of the ground for $24 \mathrm{~h}$ (as in Beard et al., 2003).

We determined the density of understory vegetation in each of the $10 \mathrm{~m} \times 10 \mathrm{~m}$ plots by measuring the percent of 100 quadrants covered on a $0.5 \mathrm{~m} \times 2 \mathrm{~m}$ coverboard (Nudds, 1977) as described by Beard (2007). We measured percent ground cover at 20 points in a $1 \mathrm{~m} \times 1 \mathrm{~m}$ quadrant by counting how many points landed on vegetation categories (forb, shrub, tree, lava, detritus, grass, moss, root, man-made). We measured canopy cover in the center of each plot using a spherical densiometer (Forest Densiometers, Bartlesville, OK).

We returned to the interviewee's property after sundown. In each plot, two researchers walked in parallel lines $2.5 \mathrm{~m}$ apart for the length of the plot $(10 \mathrm{~m})$, slowly for 15-20 min, surveying with headlamps for frogs. When we saw or heard a frog, we recorded it.

\subsection{Data analysis}

We transcribed the interview tapes verbatim and conducted content analysis of the transcripts using a method consistent with grounded theory analysis, allowing themes to come from the data rather than previously being identified by the researcher (Glaser and Strauss, 1967; Charmaz, 2003). Environmental data were averaged across the number of plots on each property to derive property-level values for each variable. To estimate frog abundance on the properties, we averaged the total number of frogs seen or heard on the property across plots on that property.

We performed all data analyses using SPSS version 19.0 (SPSS, Inc., Chicago, IL). To examine the first link, we used a logistic regression where the predictor variable was frog abundance (mean number of frogs per plot, square-root transformed to meet assumptions of normality) and attitude toward the coqui (negative or non-negative, see below for definitions) was the response variable. Because psychological phenomena such as attitudes may be more closely linked to participant-reported environmental conditions than actual conditions (Baldassare and Katz, 1992), we used a chi-square test to detect whether a relationship existed between interviewees' own estimates of frog abundance ( 0 frogs, 1 or 2 frogs, 3-100 frogs, hundreds of frogs, and thousands of frogs) and their attitudes toward the coqui (negative or non-negative).

We examined relationships between socio-demographic characteristics and attitude toward the coqui by collecting general descriptive statistics and using correlation analysis to look at relationships between various socio-demographic variables (age, gender, income, born in Hawaii, property ownership, east/west side of the island) and attitude.

To examine the relationship between attitudes and management behaviors, we first looked at the entire survey sample $(N=87)$ using a chi-square test to determine if there was a relationship between whether a person managed for coqui (yes or no) and their attitude toward the frog (negative or non-negative). We then conducted the same test including only individuals who believed they had frogs on their property $(N=50)$. For 18 individuals who believed they had coqui on their property and had responded with management action, we used a chi-square test to detect any relationship between reported use of each of the three management approaches (mechanical, chemical, and cultural) and the participant's attitude (negative or non-negative) toward the coqui. We also used a chi-square test to look for a relationship between length of time on the property ( $<1$ year, 1-19 years, $20+$ years) with attitudes toward the coqui (neg, positive, mixed).

To explore whether there was a relationship between frog abundance and residents' reported use of management practices, we used a t-test with management participation (yes or no) as the grouping variable and abundance of frogs as the test variable. We also used a chi-square test to look for a relationship between decisions to implement management (yes or no) with participant-reported coqui abundance $(0,1-2,3-100$, hundreds, and thousands).

Finally, we used regression analyses to test for relationships between frog abundance and environmental variables that potentially influence coqui abundance (canopy cover, leaf litter invertebrates, understory density). Four environmental predictor variables (\% grass, \% canopy cover, flying invertebrates, leaf litter invertebrates) were regressed upon frog abundance, square-root transformed to meet the assumption of normality. For correlation analyses, we indicate significance levels, and for all other analyses we present exact p-values. An alpha of $<0.05$ was considered significant and an alpha of 0.1 as marginally significant for all statistical tests.

\section{Results}

\subsection{Participant demographics}

Of the 87 individuals interviewed, $46 \%$ were male $(N=40)$ and $54 \%$ were female $(N=47)$, with a mean age of 53 years old (range 28 to 89 years). Property owners constituted $86 \%$ of the sample $(N=70)$, while $17 \%$ were renting $(N=15)$ and two participants declined to answer. Of those interviewed, $42 \%(N=37)$ said that they did not have frogs on their properties, while $4.6 \%$ said they had only 1 or 2 frogs $(N=4), 25.3 \%$ had between two and 100 $(N=22), 21.8 \%$ had "hundreds" $(N=19)$, and $5.7 \%(N=5)$ had "thousands or lots". Based on our nightly counts, we found coqui present on 38 properties (43.7\%). We did not detect frogs on 12 properties where respondents believed they had frogs (13.8\%), but every respondent whose properties did have the coqui knew they were present. Overall, $77 \%$ of the participants $(N=67)$ did not participate in any management for the coqui frog.

When asked to list positive and negative characteristics related to the frog, 50 people listed only negative characteristics, 6 listed only positive characteristics, and 31 listed a mixture of positive and negative characteristics. Due to the small sample size of 
Table 1

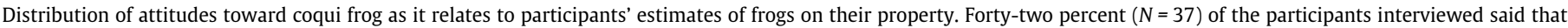

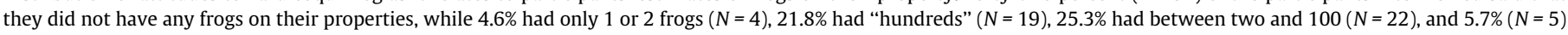
had "thousands or lots.".

\begin{tabular}{|c|c|c|c|c|c|}
\hline \multirow[t]{2}{*}{ Attitude } & \multicolumn{5}{|c|}{ People's estimate of number of coqui on their property } \\
\hline & 0 Frogs & 1 or 2 Frogs & 3-100 Frogs & Hundreds of frogs & Thousands of frogs \\
\hline Negative & 28 & 4 & 8 & 8 & 2 \\
\hline Non-negative & 8 & 0 & 14 & 11 & 3 \\
\hline
\end{tabular}

Table 2

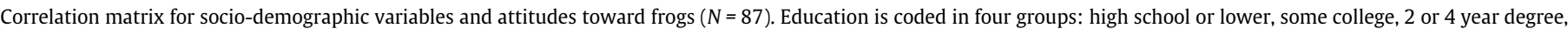

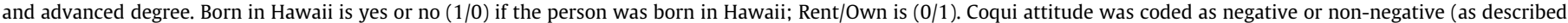

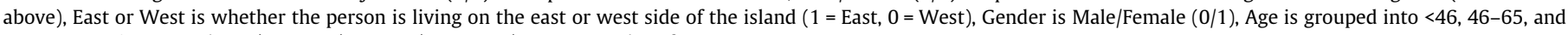
$>65$. Income is grouped as $<\$ 49,999, \$ 50,000-\$ 99,999,>\$ 100,000$, and prefer not to say.

\begin{tabular}{|c|c|c|c|c|c|c|c|c|}
\hline & Education & Born in $\mathrm{HI}$ & Rent/own & Coqui attitude & East or West & Gender & Age & Income \\
\hline Education & 1 & $-0.35^{* *}$ & .006 & 0.16 & $0.28^{* *}$ & 0.07 & -0.06 & 0.13 \\
\hline Born in $\mathrm{HI}$ ? & & 1 & 0.07 & $-0.22^{*}$ & $-0.33^{* *}$ & 0.09 & $0.24^{*}$ & 0.17 \\
\hline Rent/own & & & 1 & $-0.34^{* *}$ & 0.01 & 0.07 & 0.12 & -0.06 \\
\hline Coqui attitude & & & & 1 & $0.28^{* *}$ & -0.02 & -0.06 & 0.02 \\
\hline East or west & & & & & 1 & -0.03 & -0.12 & $-0.22^{*}$ \\
\hline Gender & & & & & & 1 & -0.02 & -0.15 \\
\hline Age & & & & & & & 1 & -0.02 \\
\hline Income & & & & & & & & 1 \\
\hline
\end{tabular}

${ }^{*} p<0.05$.

** $p<0.01$.

individuals with positive attitudes, for the remainder of our analyses we combined this group with the 31 people with mixed attitudes and categorized our attitude groups as "negative" and "non-negative". The non-negative category included individuals who only had positive things to say, as well as individuals that mentioned both, indicating a more neutral attitude. Furthermore, we found no significant differences in responses between the neutral and positive groups.

For the 6 individuals listing only positive characteristics of the frogs, they mentioned liking the sound produced, appreciating the insects consumed by the frogs, thinking the frogs benefit gardens or landscaping, getting used to the frogs and not noticing them after a period of time, and feeling that they are one of "god's creatures" and no better or worse than cars or other nighttime noises common in the area. There was no difference in length of time people had been on their property and their opinions of the frog (chi-square test with $d f=4 ; \chi^{2}=6.37, p=0.17$ ).

\subsection{Relationship of attitude to frog presence/abundance}

Participants with a negative attitude toward the coqui were 1.76 times less likely to have frogs on their property than those with non-negative attitudes $(p=0.016)$. Furthermore, people who believed they had 3 or more frogs had more positive attitudes than individuals believing they had fewer frogs (chi-square test with $d f=4 ; \chi^{2}=15.5, p=0.004$; Table 1 ).

\subsection{Relationship of socio-demographic variables and attitude}

People born in Hawaii were more likely to have a negative attitude toward the coqui than individuals not originally from the island ( $r=-0.22, n=87, p<0.05$ ). Similarly, people who own their properties had a less negative attitude compared to renters' attitudes $(r=-0.34, n=87, p<0.01)$. Individuals living on the east side of the island (where coquis have long been established and are more widespread) had less negative attitudes toward the coqui compared to individuals living on the west side of the island $(r=0.28, n=87, p<0.01$; Table 2$)$.
Table 3

Percentage of people who do or do not manage for frogs with relation to their attitude toward the coqui $(N=87)$.

\begin{tabular}{llll}
\hline & \multicolumn{2}{l}{ Do management? } & Total \\
\cline { 2 - 3 } & No & Yes & \\
\hline Negative attitude & 44.8 & 12.6 & 57.5 \\
Non-negative attitude & 32.2 & 10.3 & 42.5 \\
Total & 77.0 & 23.0 & 100 \\
\hline
\end{tabular}

\subsection{Relationship of management behavior to attitudes}

There were no differences in attitude between those who did or did not report taking management actions (chi-square test with $d f=1 ; \chi^{2}=0.065, p=0.799$; Table 3 ). Differences in attitude were not detected even after limiting the sample to those who believed they had frogs on their property (chi-square test with $d f=1$; $\chi^{2}=0.411, p=0.522$ ).

We found no differences in the relationship between attitude and the type of management practice employed (chi-square test for mechanical control with $d f=1 ; \chi^{2}=0.222, p=0.637$; chisquare test for chemical control with $d f=1 ; \chi^{2}=2.104, p=0.335$; chi-square test for cultural control with $d f=1 ; \chi^{2}=0.0, p=1.00$ ).

of the 20 people who reported engaging in management behaviors, two reported doing so although they believed they did not have frogs. Both were proactively checking plants before purchase to prevent spreading frogs from the store to their home.

\subsection{Relationship of management behavior to frog presence/abundance}

On average, frog density was higher on properties where residents said they had engaged in management activities $(t=1.02$, $p=0.005$ ). We found no relationship between participant's selfreported density of frogs on a property and their self-reported management of the frogs (chi-square test with $d f=3 ; \chi^{2}=3.34$, $p=0.342)$.

In total, nine participants conducted mechanical, 11 participants conducted chemical, and 10 participants conducted cultural 
management ( $N>20$ because some participants used more than one form of management). We found no relationship between type of management and participant-reported estimates of frogs on a property (chi-square test for mechanical control with $d f=3$; $\chi^{2}=3.45, p=0.328$; chi-square test for chemical control with $d f=3 ; \chi^{2}=4.34, p=0.227$; chi-square test for agricultural control with $d f=1 ; \chi^{2}=6.28, p=0.099$ ).

\subsection{Relationship between environmental variables and frog abundance}

Several environmental variables were correlated with each other (Table 4). The overall model was marginally significant $(F=2.054, p=0.094)$, with canopy cover as the only significant predictor of frog counts ( $p=0.019$; Table 5$)$.

\section{Discussion}

To better understand the variables affecting the coqui invasion on the island of Hawaii, we employed an SES framework. We found support for our first set of predictions from the SES framework, linking abundance and socio-demographic variables to attitudes. Coqui abundance was related to attitudes, but not in the expected direction: People with more frogs on their property tended to have less negative attitudes toward the coqui. Furthermore, those who owned that property and those living on the east side of the island, who have had longer exposure and experience with the frogs, tended to have less negative attitude toward the coqui. This suggests that many people who are more likely to be affected negatively in terms of property values, and who are living in areas with more frogs, have become habituated to them.

Habituation to frogs could result from external influences or a shift in internal preferences of individual property owners. People not yet living with the coqui are bombarded with negative images from the media including complaints about the volume of frog calls, which is said to affect the ability to sleep (Bernardo, 2002) and result in a possible decrease in property value (Kaiser and Burnett, 2006). While only $7 \%$ of our participants had only positive things to say about the coqui, these individuals mentioned they liked the frog's sound, appreciated that the frogs consumed a large number of insects, felt that the frogs helped in garden productivity, and believed that the frogs were one of "god's creatures" and were no better or worse than other common nighttime noises. Thus, people with positive beliefs toward the coqui appear unaffected by government information campaigns regarding the coqui. These individuals may have had negative attitudes that were later altered by interaction with the coquis or they may simply not agree with the negative information.

There are several other potential reasons for positive or neutral attitudes that were not specifically addressed in the survey; for example, respondents could be hard of hearing, or work at night and not be kept awake by frog calls. One participant did mention lack of hearing as a reason for not being upset by the frogs, and another potential participant declined to do our survey because he had never heard the frogs due to hearing loss and therefore did not have an opinion. Furthermore, just because a species is considered a pest by the government does not mean that all individuals are directly affected by that species, but rather that the species may have negative impacts on the economy, environment, or human health and safety. Individuals may not experience these effects personally and therefore may not agree with them, as is commonly seen in addressing environmental behavior change (Vugt et al., 2014). Finally, Hawaii has such a high percentage of introduced species (80.5\% of mammal species are introduced; $52.5 \%$ of birds; $91.3 \%$ of reptiles and amphibians; (Staples and

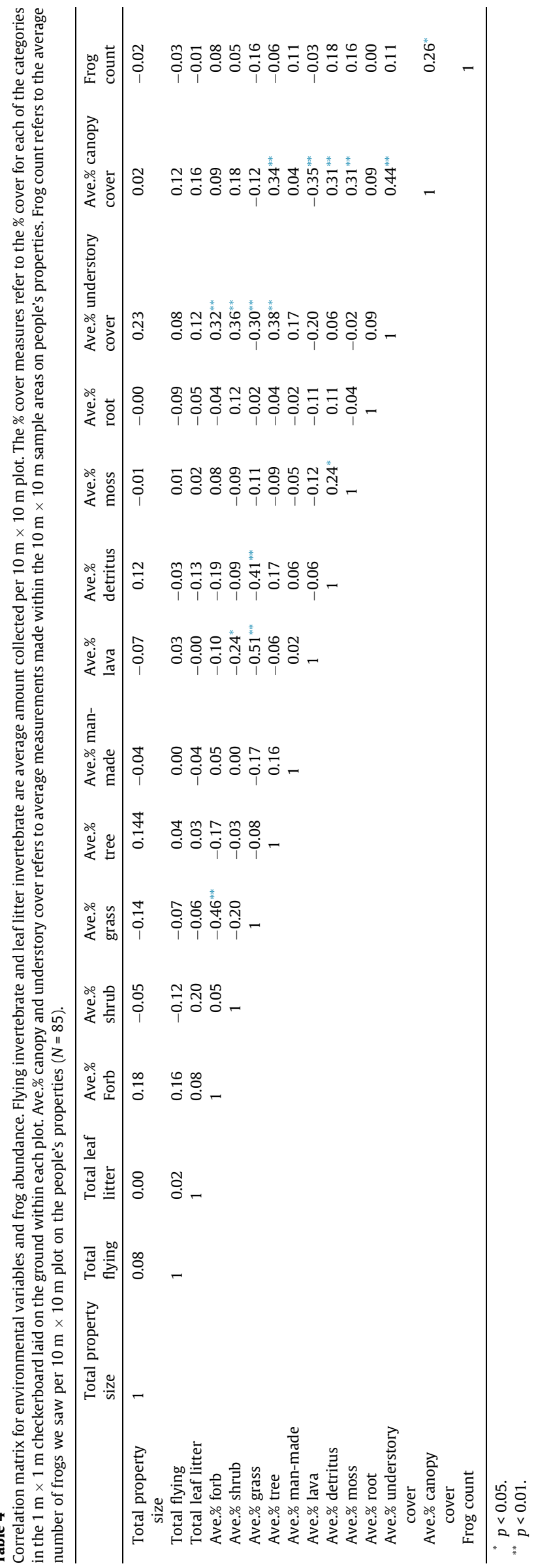


Table 5

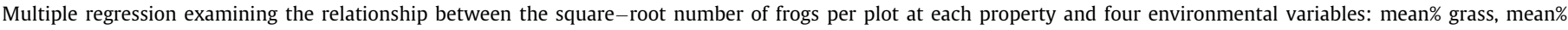
canopy cover, flying invertebrates abundance, and leaf litter invertebrates abundance $(N=87)$.

\begin{tabular}{|c|c|c|c|c|}
\hline & Unstandardized coefficient b & Std. error & $t$ & Sig \\
\hline Constant & 0.536 & 0.268 & 2.001 & 0.049 \\
\hline$\%$ Grass & -0.004 & 0.003 & -1.289 & 0.201 \\
\hline \% Canopy cover & 0.008 & 0.003 & 2.383 & 0.019 \\
\hline Flying invertebrates & -0.003 & 0.004 & -0.669 & 0.505 \\
\hline Leaf litter invertebrates & -0.001 & 0.001 & -0.557 & 0.579 \\
\hline
\end{tabular}

$p<0.05$.

Cowie, 2001), that general attitudes toward non-native species may be different in Hawaii compared to the mainland. This topic warrants further research.

Property owners may hold less negative attitudes because they have greater levels of attachment to their properties and therefore greater investment in staying where they live. They therefore may want to believe that their property value has not been lowered, thus, offsetting the undesirable consequences of coqui invasion. Alternatively, property owners who originally held less negative attitudes may have been more likely to purchase a property that already had frogs. Similarly, those living on the east coast of the island may have moved there or stayed there because they already had less negative attitudes while those with more negative attitudes may move to the west coast. We found that renters had more negative attitudes toward coquis. It would appear that renters would be more flexible in terms of their housing choices, but other factors may be more important in choosing a housing location (including price, neighborhood vicinity to work, etc). For those home owners harboring positive or neutral beliefs toward the coqui, cognitive dissonance theory (Festinger, 1957) may be occurring, which suggests that when attitudes are inconsistent with behaviors, people may be motivated to change or reduce the strength of the attitude to reduce psychological discomfort that comes from inconsistency between what one thinks and what one does. Further examination of the causes for the positive or neutral beliefs could help discern the cause or development of the belief and determine when or if a shift in attitude or management behavior occurred. If cognitive dissonance theory is a strong predictor of beliefs and behavior, managers interested in behavior change could focus on campaigns to reduce the dissonance.

The second set of predictions from the SES framework - that negative attitudes and higher coqui abundance would be associated with actions taken to reduce abundance - was only partially supported. While we found frogs to be more abundant where people reported having engaged in management, we found no relationship between negative attitudes and control activities. Higher abundances where there is more management may suggest that people are more likely to take action where the problem is greater and/or it may suggest that the management actions taken were insufficient to have an effect. Additionally, although we located frogs on nearly half of the properties surveyed, fewer than $25 \%$ of our respondents took management action to reduce or prevent coqui invasion. We cannot determine from our study why so few people take action to reduce populations.

It is not uncommon for researchers to find that attitudes about an object do not lead to actions toward that object (Ajzen, 1991). In the case of the coqui, this may be due to perceptions about the difficulty of taking a management action or a lack of education on the most effective management strategies suggested by the local government. Other studies have found that the amount of time, money, or equipment necessary to conduct non-native species control can be strongly related to whether an individual will do management (Stokes et al., 2006; Epanchin-Niell et al., 2010). In Hawaii, citric acid treatment is relatively expensive and requires direct application to manage coqui populations effectively, often necessitating repeated treatments (Beard and Pitt, 2005; Anonymous, 2010). While we did not collect data on the perceived difficulty of performing management behaviors, we did find two individuals who were proactively engaged in management by checking plants before purchase to prevent spreading frogs from the store to their home. This type of behavior does not require special equipment and has a small time investment, and may therefore be a behavior that could be encouraged by managers if the effect of the frog on society and the environment warrants such a behavior. Several participants indicated that they learned about the coqui through various news outlets; however, as one of our participants stated very clearly, information on management and effects of the coqui needs to be more specific for homeowners to understand what action need to be taken and why. It would be useful to explore how important time, money, understanding, and accessibility of equipment is for management behavior in future research because greater understanding allows for education and outreach efforts to be designed to make residents more comfortable with the control options available to them.

The positive relationship between coqui abundance and canopy cover supports our last prediction in our SES model. Previous research in Hawaii suggests a positive relationship between understory structure and coqui density (Stewart and Pough, 1983; Beard et al., 2008) and the amount of canopy cover was positively related to amount of understory cover on private properties. Our results suggest that property owners who remove canopy cover as well as plants beneath the forest canopy may be able to reduce coqui abundance.

While the majority of the participants were not actively managing the coqui, those who were doing so used forms of habitat manipulation or chemical application that could alter some of the environmental variables discussed in the previous paragraph. The local government has labeled the coqui a "pest" and "injurious wildlife" and advocated control or eradication. While the government's position on the coqui does not appear to consider any potential societal or ecological benefits of coqui frogs, helping to educate people on the most effective management and why people should want to do so seems critical in achieving the government's goals of control or eradication (Anonymous, 2010). Coquis change invertebrate communities (Choi and Beard, 2012), and increase non-native plant growth rates (Sin et al., 2008), which may be considered detrimental or beneficial effects to the ecosystem (in the case of reducing non-native invertebrates) and these effects may not be known or cared about by home owners. Many participants expressed an interest in understanding more about the ecological effects of the frog including what the frogs are consuming, to better understand efforts to control them (Kalnicky, 2012). On the other hand, quantifying potential health benefits seen by the "calming" sound of the frogs or reduction of unwanted insects mentioned by our participants is necessary to capture fully the societal and ecological effects connected to the introduction of this non-native frog in Hawaii.

Social-ecological systems approaches offer a new, crossdisciplinary method for understanding dynamics of non-native species introductions (Roy et al., 2010; Sundaram et al., 2012). In our case study, we were able to illuminate relationships between 
environmental and social variables that influence how individuals perceive a non-native species and its effects, as well as the abundance of that species. We also found evidence as to why efforts to enlist citizens in coqui control on the island have not succeeded as well as they might. Residents of the island of Hawaii appear to be learning to live with the coqui. Tolerance for the non-native species is likely to hinder efforts to engage residents in coqui control as the species' range on the island continues to expand. Even when residents have negative attitudes, those attitudes do not necessarily lead to action taken against the coqui. Managers attempting to control the coqui would benefit by educating individuals on the effects of the frog and how management behavior directly affects the property owner.

Possible habituation to the coqui represents the most unexpected finding of this research. A few other non-natives, e.g., Eucalyptus in California and ring-necked pheasant (Phasianus colchicus) in much of North America, have become cultural icons in their new ranges (Nuñez and Simberloff, 2005; Simberloff et al., 2013), but for the most part these species were deliberately introduced for human benefits and strong cultural appreciation preceded any recognition of negative effects. We could find no other documented example of people increasingly accepting a non-native animal that has been found to have negative effects on people living in a given area or on the environment in those areas. Further research would be useful to document and explain the factors underlying possible habituation to non-native species in this and other situations.

\section{Conclusion}

As globalization continues to facilitate the spread of non-natives to new areas (Meyerson and Mooney, 2007), the possibility of habituation likewise increases. In cases where the effect of a non-native species is not yet widespread (i.e., early in the invasion process), efforts to engage citizens in non-native species control is difficult. For example, in Italy, protests by animal rights groups delayed efforts to eradicate the American grey squirrel (Sciurus carolinensis) until eradication was no longer feasible (Bertolino and Genovesi, 2003). Similarly in Hawaii, there was resistance to using caffeine to control coquis even though this is the most effective chemical to control them (Pitt, pers. comm.). Not only does it become more expensive to control species as they become more widespread, but it also because more difficult if habituation occurs. Habituation can be viewed as either a positive or a negative result depending upon the social-ecological system in question. For a species with negative social-ecological effects, an initial influx of resources early could be beneficial in achieving long-term goals of control or eradication, as possible habituation could mean effort spent on changing attitudes may be less effective over time. Efforts to reduce time to habituation should include education and outreach on potential societal and/or ecological benefits. In the case where a non-native species is unlikely to have long-term detrimental effects on social or ecological systems, it is possible that a wait-and-see approach may be beneficial in reducing money spent attempting to control or eradicate the species, especially if habituation is likely.

\section{Acknowledgments}

This research was supported by a Quinney Doctoral Fellowship for the lead author, and by the Utah Agricultural Experiment Station and Ecology Center, Utah State University. This research was conducted under amended Utah State University IACUC permit \#1356 and IRB permit \#2061; and State of HI DLNR Scientific Permit for Native Invertebrates \#: FHM08-162. Field support in Hawaii was provided by W. Pitt and the USDA Hilo Field Station. Laboratory and/or field assistance was provided by L. Johnson and S. Price. This research was supported by the Utah Agricultural Experiment Station, Utah State University, and approved as journal paper number 8716 .

\section{References}

Ajzen, I., 1991. Theory of planned behavior. Organ. Behav. Hum. Decis. Process. 50, $179-211$.

Anonymous, 2010. Hawai'i's coqui frog management, research and education plan (ed DLNR-DOFAW, County of Hawaii, USDA/WS, BIISC, HDOA). URL: <http:// dlnr.hawaii.gov/hisc/files/2013/02/20071217coquiplandraft.pdf>.

Baldassare, M., Katz, C., 1992. The personal threat of environmental problems as predictor of environmental practices. Environ. Behav. 24, 602-616.

Barr, J.J.F., Lurz, W.W.P., Shirley, M.D.F., Rushton, S.P., 2002. Evaluation of immunocontraception as a publicly acceptable form of vertebrate pest species control: the introduced grey squirrel in Britain as an example. Environ. Manage. 30, 342-351.

Beard, K.H., 2007. Diet of the invasive frog, Eleutherodactylus coqui, in Hawaii Copeia 2, 281-291.

Beard, K.H., Pitt, W.C., 2005. Potential consequences of the coqui frog invasion in Hawaii. Divers. Distrib. 11, 427-433.

Beard, K.H., Pitt, W.C., 2012. Chapter 26: Caribbean tree frog (Eleutherodactylus coqui). pp. 311-319. In: Francis, Robert A. (Ed.), Handbook of Global Freshwater Invasive Species. Earthscan, London.

Beard, K.H., McCullough, S., Eschtrut, A.K., 2003. Quantitative assessment of habitat preference for the Puerto Rican terrestrial frog, Eleutherodactylus coqui. J. Herpetol. 37, 10-17.

Beard, K.H., Al-Chokhachy, R., Tuttle, N.C., O’Neill, E.M., 2008. Population density and growth rates of Eleutherodactylus coqui in Hawaii. J. Herpetol. 42, 626636.

Beard, K.H., Price, E.A., Pitt, W.C., 2009. Biology and impacts of Pacific Island invasive species: 5. Eleutherodactylus coqui, the coqui frog (Anura: Leptodactylidae). Pac. Sci. 63, 297-316.

Bernardo, R. (Tuesday, September 24, 2002). Coqui frogs get reprieve from deadly caffeine buzz. A federal agency suspends a permit to use the pesticide on the noisy critters. Honolulu Star Bulletin.

Bertolino, S., Genovesi, P., 2003. Spread and attempted eradication of the grey squirrel (Sciurus carolinensis) in Italy, and consequences for the red squirre (Sciurus vulgaris) in Eurasia. Biol. Conserv. 109, 351-358.

Bisrat, S.A., White, M.A., Beard, K.H., Cutler, D.R., 2012. Predicting the distribution potential of an invasive Puerto Rican frog (Eleutherodactylus coqui) in Hawaii using remote sensing data. Divers. Distrib. 18, 648-660.

Bodin, Ö., Tengö, M., 2012. Disentangling intangible social-ecological systems. Global Environ. Change 22, 430-439.

Charmaz, K., 2003. Qualitative interviewing and grounded theory analysis. pp. 311330. In: Gubrium, J.F., Holstein, J.A. (Eds.), Inside Interviewing: new lenses, new concerns (pp. 311-330). Sage Publications, Thousand Oaks, California, USA.

Choi, R.T., Beard, K.H., 2012. Coqui frog invasions change invertebrate communities in Hawaii. Biol. Invasion 14, 939-948.

Chowdhury, R., Larson, K., Grove, M., Polsky, C., Cook, E., Onsted, J., Ogden, L., 2011. A multi-scalar approach to theorizing socio-ecological dynamics of urban residential landscapes. Cities and the Environ. (CATE) 4 (1), 6.

Coates, P., 2006. American perceptions of immigrant and invasive species. Strangers on the land. University of California Press, Berkeley, California, USA.

Cook, E.M., Hall, S.J., Larson, K.L., 2012. Residential landscapes as social-ecological systems: a synthesis of multi-scalar interactions between people and their home environment. Urban Ecosyst. 15, 19-52.

Epanchin-Niell, R.S., Hufford, M.B., Aslan, C.E., Jason, P.S., Port, J.D., Waring, T.M. 2010. Controlling invasive species in complex social landscapes. Front. Ecol. Environ. 8, 210-216.

Festinger, L., 1957. A Theory of Cognitive Dissonance. Stanford University Press, Stanford, California, USA.

Fitzgerald, G., Fitzgerald, N., Davidson, C., 2007. Public attitudes towards invasive animals and their impacts: University of Canberra, Australia.

Folke, C., 2006. Resilience: the emergence of a perspective for social-ecological systems analysis. Global Environ. Change 16, 253-267.

Fraser, A., 2006. Public attitudes to pest control. A literature review. Science and Technical Publishing, Wellington, New Zealand.

Fujimori, L., 2001. Shrieking frogs invade Oahu. The call of the coqui irritates residents and worries agricultural officials. Honolulu Star-Bulletin.

Glaser, B.G., Strauss, A.L., 1967. The Discovery of Grounded Theory: Strategies for Qualitative Research. Aldine, Chicago, Illinois, USA.

Gonzalez-Pagan, O., 2007. Hawaii residents' attitudes towards the management of an invasive frog species (Eleutherodactylus coqui). Thesis. Cornell University, Ithaca, New York, USA

Heong, K.L., Escalade, M.M., Huan, N.H., Mai, V., 1998. Use of communication media in changing rice farmers' pest management in the Mekong Delta, Vietnam. Crop Protect. 17, 413-425.

Hills, A.M., 1993. The motivational bases of attitudes toward animals. Soc. Anim. 1 $111-128$.

ISSG, 2005. Ecology of Eleutherodactylus coqui (Publication from National Biological Information Infrastructure (NBII)

Joglar, R., 1998. Los coquies de Puerto Rico. Su historia natural y conservacion. University of Puerto Rico Press, San Juan, Puerto Rico. 
Kaiser, B.A., Burnett, K., 2006. Economic impacts of E. coqui frogs in Hawaii. Interdisciplin. Environ. Rev. 8, 1-12.

Kalnicky, E.A., 2012. A coupled human and natural systems approach to understanding an invasive frog, Eleutherodactylus coqui, in Hawaii. Dissertation. Utah State University, Logan.

Kalnicky, E.A., Beard, K.H., Brunson, M.W., 2013. Community-level response to habitat structure manipulations: an experimental case study in a tropical ecosystem. For. Ecol. Manage. 307, 313-321.

Kempton, W., Boster, J.S., Hartley, J.A., 1995. Environmental values in American culture. MIT Press, Cambridge, UK.

Kraus, F., Campbell, E.W., 2002. Human-mediated escalation of a formerly eradicable problem: the invasion of Caribbean frogs in the Hawaiian Islands. Biol. Invasions 4, 327-332.

Kraus, F., Campbell, E.W., Allison, A., Pratt, T., 1999. Eleutherodactylus frog introductions to Hawaii. Herpetolog. Rev. 30, 21-25.

Meyerson, L.A., Mooney, H.A., 2007. Invasive alien species in an era of globalization. Front. Ecol. Environ. 5, 199-208.

Miller, K.K., Jones, D.N., 2005. Wildlife management in Australasia: perceptions of objectives and priorities. Wildl. Res. 32, 265-272.

Miller, K.K., Jones, D.N., 2006. Gender differences in the perceptions of wildlife management objectives and priorities in Australasia. Wildl. Res. 33, 155-159.

Mooney, H.A., 2005. Invasive alien species: the nature of the problem. Island Press, Washington DC, USA.

Nudds, T., 1977. Quantifying the vegetative structure of wildlife cover. Wildl. Soc. Bull. 5, 113-117.

Nuñez, M.A., Simberloff, D., 2005. Invasive species and the cultural keystone species concept. Ecol. Soc. 10 (1), r4.

Pitt, W.C., Beard, K.H., Doratt, R., 2012. Management of invasive coqui frog populations in Hawaii. Outlooks Pest Manage. 23 (4), 166-169.

Reaser, J.K., 2001. Invasive alien species prevention and control: the art and science of managing people. In: McNeely, J.A. (Ed.), The Great Reshuffling: Human Dimensions of Invasive Alien Species. IUCN, Gland, Switzerland and Cambridge, UK, pp. 89-104.

Rivero, J.A., 1998. Los anfibios y reptiles de Puerto Rico. University of Puerto Rico Press, San Juan, Puerto Rico.

Roy, E.D., Martin, J.F., Irwin, E.G., Conroy, J.D., Culver, D.A., 2010. Transient socialecological stability: the effects of invasive species and ecosystem restoration on nutrient management compromise in Lake Erie. Ecol. Soc. 15, 1.
Ruiz, G.M., Carlton, J., 2003. Invasive Species: Vectors and Management Strategies. Island Press, Washington, DC, USA.

Schwartz, A., Henderson, R.W., 1991. Eleutherodactylus coqui Thomas, 1996. In Amphibians and reptiles of the West Indies: descriptions, distributions, and natural history. University Press of Florida, Gainesville, Florida, USA.

Simberloff, D., Martin, J.L., Genovesi, P., Maris, V., Wardle, D.A., Aronson, J., Courchamp, Franck, Galil, Bella, García-Berthou, Emili, Pascal, Michel, Pyšek, Petr, Sousa, Ronaldo, Tabacchi, Eric, Vila, M., 2013. Impacts of biological invasions: what's what and the way forward. Trends Ecol. Evol. 28, 58-66.

Sin, H., Beard, K.H., Pitt, W.C., 2008. An invasive frog, Eleutherodactylus coqui, increases new leaf production and leaf litter decomposition rates through nutrient cycling in Hawaii. Biol. Invasions. 10, 335-345.

Singer, S.R., Grismaijer, S., 2005. Panic in paradise: invasive species hysteria and the Hawaiian coqui frog war (Environmentalism gone mad!). ISCD Press, Pahoa, Hawaii, USA.

Staples, G.W., Cowie, R.H. (Eds.), 2001. Hawaii's Invasive Species: A Guide to the Invasive Alien Animals and Plants of the Hawaiian Islands. Mutual Publishing and Bishop Museum Press, Honolulu, 118 p.

Stewart, M.M., Pough, F.H., 1983. Population density of tropical forest frogs: relation to retreat sites. Science 221, 570-572.

Stewart, M.M., Rand, S., 1992. Diel variation in the use of aggressive calls by the frog Eleutherodactylus coqui. Herpetologica 48, 49-56.

Stewart, M.M., Woolbright, L.L., 1996. Amphibians. In: Reagan, D.P., Waide, R.B. (Eds.), The Food Web of a Tropical Rain Forest. University of Chicago Press, Chicago, Illinois, USA, pp. 363-398.

Stokes, K. E O'Neill, K. P. Montgomery, W. I, Dick, JT A, Magos, C.A. McDonald, R.A. 2006. The importance of stakeholder engagement in invasive species management: a cross-jurisdictional perspective in Ireland. Biodivers. Conserv. $15,2829-2852$.

Sundaram, B., Krishnan, S., Hiremath, A.J., Joseph, G., 2012. Ecology and impacts of the invasive species, Lantana camara, in a social-ecological system in South India: perspectives from local knowledge. Human Ecol. 40 (6), 931-942.

Vugt, M., Griskevicius, V., Schultz, P., 2014. Naturally green: harnessing stone age psychological biases to foster environmental behavior. Soc. Issues Policy Rev. 8 (1), 1-32.

Woolbright, L.L., 1985. Patterns of nocturnal movement and calling by the tropical frog Eleutherodactylus coqui. Herpetologica 4, 1-9. 